This document was prepared in conjunction with work accomplished under Contract No. DE-AC09-96SR18500 with the U.S. Department of Energy.

This work was prepared under an agreement with and funded by the U.S. Government. Neither the U. S. Government or its employees, nor any of its contractors, subcontractors or their employees, makes any express or implied: 1 . warranty or assumes any legal liability for the accuracy, completeness, or for the use or results of such use of any information, product, or process disclosed; or 2 . representation that such use or results of such use would not infringe privately owned rights; or 3 . endorsement or recommendation of any specifically identified commercial product, process, or service. Any views and opinions of authors expressed in this work do not necessarily state or reflect those of the United States Government, or its contractors, or subcontractors. 
WM'08 CONFERENCE, FEBRUARY 24 - FEBRUARY 28, 2008, TUCSON, AZ

WSRC-STI-2008-00097

\title{
STUDIES OF POTENTIAL INHIBITORS OF SODIUM ALUMINOSILICATE SCALES IN HIGH-LEVEL WASTE EVAPORATION
}

\author{
L. N. Oji, T.L. Fellinger, D. T. Hobbs, N. P. Badheka, and W. R. Wilmarth, \\ Savannah River National Laboratory \\ Defense Waste Processing Facility \\ Westinghouse Savannah River Company \\ P. O. Box X \\ Aiken, SC 29808 \\ USA
}

\begin{abstract}
The Savannah River Site (SRS) has 49 underground storage tanks used to store High Level Waste (HLW). The tank space in these tanks must be managed to support the continued operation of key facilities. The reduction of the tank volumes in these tanks are accomplished through the use of three atmospheric pressure HLW evaporators. For a decade, evaporation of highly alkaline HLW containing aluminum and silicates has produced sodium aluminosilicate scales causing both operation and criticality hazards in the $2 \mathrm{H}$ Evaporator System. Segregation of aluminum-rich wastes from silicaterich wastes minimizes the amount of scale produced and reduces cleaning expenses, but does not eliminate the scaling nor increases operation flexibility in waste process. Similar issues have affected the aluminum refining industry for many decades. Over the past several years, successful commercial products have been identified to eliminate aluminosilicate fouling in the aluminum industry, but have not been utilized in a nuclear environment.
\end{abstract}

Laboratory quantities of three proprietary aluminosilicate scale inhibitors have been produced and been shown to prevent formation of scales. SRNL has been actively testing these potential inhibitors to examine their radiation stability, radiolytic degradation behaviors, and downstream impacts to determine their viability within the HLW system. One of the tested polymers successfully meets the established criteria for application in the nuclear environment. This paper will describe a summary of the methodology used to prioritize laboratory testing protocols based on potential impacts/risks identified for inhibitor deployment at SRS.

\section{INTRODUCTION}

Effective mitigation of scale formation in process plants is a serious issue of major scientific and technological challenge to the mineral, chemical, petrochemical, power generation and food processing industries worldwide. Many industrial operations involve intensive heating and cooling operations performed in heat exchangers where fouling tends to be most profound. Fouling management or mitigation methods usually require enormous human effort with plant personnel manually de-scaling equipment off-line using highly corrosive, acidic/caustic reagents and/or power tools. Sodium aluminosilicate (NAS) scale deposition occurs in heat exchangers and other vessels of caustic media processing industries such as Bayer process alumina refineries [1 - 4], and Kraft pulp and paper closed cycle mills [5 - 7], and the evaporation of highly alkaline nuclear wastes [8,9]. Fouling can be so severe that complete blockage of alumina plant tubular heat exchangers may sometimes occur within 4 - 6 weeks of operation. Where NAS fouling occurs in nuclear waste processing, dissolved radionuclides (e.g. uranium-235, plutonium-238 and cesium-137) may also exceed their solubility limits. This eventually causes mixed NAS - radionuclide precipitation and fouling introducing criticality issues for cleaning operations [10 -12]. 


\section{WM'08 CONFERENCE, FEBRUARY 24 - FEBRUARY 28, 2008, TUCSON, AZ WSRC-STI-2008-00097}

The development of potential NAS inhibitors has been studied for many decades. Addai-Mensah, et al. [13] describes use of an unidentified polymeric additive that reduced sodalite scaling on steel surfaces by $\sim 37 \%$ at a dosage of $300 \mathrm{mg} / \mathrm{l}$. Personnel from Cytec Industries [14] showed that a patented product could eliminate scaling in the Bayer industry and have been successfully introducing this product worldwide. SRNL and Cytec Industries entered into a Cooperative Research and Development Agreement to develop an inhibitor technology for nuclear waste operations.

Assuming the inhibitor technology development was successful in the nuclear waste processing matrix, the application at the SRS would need to protect not only safety but additionally preventing downstream impacts. Therefore, an examination of potential downstream impacts was performed. These "risks" were ranked against cost, schedule and safety implications. Table I shows a breakdown of the risks by facility. This format allowed for a prioritization of testing protocols such that those with either the highest impact or longest implementation could be addressed. As inhibitor development progressed, Cytec made available three different materials that performed successfully in simulated SRS waste matrices.

Table I. Listing of the Number of Potential Impacts/Risks Identified for Inhibitor Deployment

\begin{tabular}{|c|c|}
\hline Process Impacted & $\begin{array}{l}\text { Number and Category of } \\
\text { Risks }\end{array}$ \\
\hline Evaporator Operation & $\begin{array}{l}5 \text { High } \\
3 \text { Medium } \\
2 \text { Low }\end{array}$ \\
\hline Tank Farm Storage & $\begin{array}{l}1 \text { High } \\
3 \text { Medium } \\
2 \text { Low }\end{array}$ \\
\hline Salt Retrieval & $\begin{array}{l}1 \text { High } \\
1 \text { Medium } \\
3 \text { Low } \\
\end{array}$ \\
\hline Alpha Removal & $\begin{array}{l}1 \text { High } \\
5 \text { Medium }\end{array}$ \\
\hline Solvent Extraction & $\begin{array}{l}1 \text { High } \\
4 \text { Medium }\end{array}$ \\
\hline Saltstone & $\begin{array}{l}2 \text { High } \\
1 \text { Medium } \\
12 \text { Low } \\
\end{array}$ \\
\hline Defense Waste Processing & $\begin{array}{l}4 \text { High } \\
5 \text { Medium } \\
1 \text { Low } \\
\end{array}$ \\
\hline Sludge Processing & $\begin{array}{l}2 \text { High } \\
3 \text { Medium }\end{array}$ \\
\hline Effluent Treatment & $\begin{array}{l}1 \text { Medium } \\
2 \text { Low }\end{array}$ \\
\hline
\end{tabular}




\section{WM'08 CONFERENCE, FEBRUARY 24 - FEBRUARY 28, 2008, TUCSON, AZ WSRC-STI-2008-00097}

\section{EXPERIMENTAL}

Cytec Industries, Inc. provided three proprietary inhibitors for testing. The polymers for this paper are labeled Epsilon, Omega and Tau. These three prospective agents were evaluated to determine their laboratory scale performance capabilities in the suppression of sodium aluminosilicate formation, ability to not cause downstream problems and understand the fate of the inhibitors in the High Level Waste System. Specifically, testing was performed in the following areas:

- NAS Suppression as a function of radiation dose

- Radiolytic Stability of the inhibitors

- Fate of the inhibitors during evaporator operation

- Impact on actinide chemistry, and

- Impact on Caustic-Side Solvent Extraction

For tasks involving irradiations, simulated waste solutions containing applicable anions with sodium concentrations around $6 \mathrm{M}$ were placed into a Shepard Model 484 cobalt-60 gamma irradiator. Tasks involving sodium aluminosilicate formation testing, the salt solution containing aluminate ions and the inhibitor were irradiated to a predetermined dose, removed from the source, an aliquot of a sodium metasilicate solution was added, and the vessel heated at $100{ }^{\circ} \mathrm{C}$ for several hours. After cooling, the slurry was filtered and the total amount of solids presumably sodium aluminosilicate were recovered and weighed. The amount of solids recovered for tests with the inhibitor were compared to control tests without an inhibitor addition. Additionally, solution samples will be sent to an offsite laboratory for measuring the concentration of the antiscalant polymer to determine the expected duration the antiscalant polymer will survive in the radiation field.

The purpose of some of the tests was to screen the antiscalant polymer for impacts on actinides contained in the High Level Waste. If the polymer can form a soluble complex with the actinides, there exists a higher demand on the alpha removal process. Conversely, if the polymer will precipitate the actinides and remove the actinides from solution without precipitating neutron poisons, a nuclear criticality strategy would be needed to assure nuclear safety.

These tests in concept were very similar. A simulant was prepared and the antiscalant polymer was added and samples are removed periodically for actinide concentration by Inductively Coupled Plasma - Mass Spectrometry (ICP-MS) and alpha pulse height analysis. In the complexation task, a simulant comprised of high salt content (nitrate/nitrite) and low hydroxide and carbonate was used. In the precipitation testing, a simulant with the opposite character was used. In either case, a control experiment was conducted. These tests examined solution phase concentration of the actinides for a period of 2 months. The kinetics and capacity of the monosodium titanate sorbent used in the Salt Waste Processing Facility process was examined for solutions containing each of the potential inhibitors and compared to control tests without inhibitor.

Additionally, to screen for impacts to the solvent extraction process for cesium removal, personnel have often used an ESS methodology, where ESS stands for Extraction, Scrub and Strip. In these tests, a known amount of waste simulant is contacted with the solvent in the extraction step. The solvent is then in a stepwise fashion contacted with the scrub and strip solutions. Tests used a simulant that is 6 M sodium with $4 \mathrm{M}$ hydroxide and $1 \mathrm{M}$ nitrate and nitrite. The solution will be spiked with a Cs-137 tracer. 


\section{WM'08 CONFERENCE, FEBRUARY 24 - FEBRUARY 28, 2008, TUCSON, AZ WSRC-STI-2008-00097}

Three subtasks will screen for the fate of the polymer additive to the SRS High Level Waste system. Experience in using these types of polymers in the aluminum industry indicates that the antiscalant will deposit on iron-containing solids, e.g. red-mud. This indicates that interactions such as sorption onto sludge particles that are high in iron species are a possibility. If such sorption does occur, there exist possible processing issues such as carbon loading in the Defense Waste Processing Facility melter, hydrogen or other flammable gas generation during storage from the high radiation dose rates. Therefore, a sorption test was performed wherein an amount of sludge will be contacted with a simulant containing the antiscalant polymer near its solubility limit. After 168 hours of agitated contact the sludge was allowed to settle and a solution phase sample was taken and analyzed for the antiscalant concentration.

With the antiscalant polymer entering the evaporator system, two other mechanisms exist to remove the polymer from solution other than radiological and chemical degradation (for testing see section on NAS suppression and radiological lifetime). These mechanisms are sorption or occlusion into saltcake. For examining sorption onto saltcake, a test similar to that just describe for sorption onto sludge was conducted. In this test, a saturated salt solution with the antiscalant polymer concentration near its solubility limit was contacted with a previously prepared saltcake. The contact duration was 168 hours and the samples were obtained periodically during the test. The samples were analyzed for the antiscalant concentration.

Lastly, occlusion of the polymer into the pores in the saltcake is a possible mechanism to remove the agent from the evaporator system. In this testing, a simulant containing $300 \mathrm{ppm}$ of the antiscalant was evaporated to produce saltcake. Upon formation, a know mass of saltcake was dissolved and the resulting solution was analyzed for the antiscalant polymer.

An "actual" waste test, one designed to examine the effectiveness of the inhibitors in the presence of nuclear waste obtained directly from an SRS nuclear waste tanks, was also performed. The tests examined control tests without antiscalant polymers versus ones in which the antiscalant polymer was added. The radioactive waste sample used for this section of the tests was composite nuclear waste supernate sample which was used in a previous study [15]. For this test, adjustments for free-OH, silicon and boron levels were made to bring their concentration levels, respectively, to 4.0 molar, 687.5 $\mathrm{mg} / \mathrm{L}$, and $0.2216 \mathrm{mg} / \mathrm{L}$. This level of boron ensured that the silicon to boron ratio was 3:1, which is assumed to be typical of SRS nuclear waste stream in general. The final adjusted levels for free-OH and silicon were analytically determined to be, respectively, 5.30 molar and $758 \mathrm{mg} / \mathrm{L}$. The density of the resulting adjusted composite solution was $1.25 \mathrm{~g} / \mathrm{mL}$.

In these actual waste tests, each inhibitor agent, at 300 ppm levels, was mixed thoroughly with $125 \mathrm{~g}$ of the adjusted composite nuclear waste in different 250 -mL capacity poly-bottles before introduction of the mixture into a reflux reaction vessel. After heating $\left(100^{\circ} \mathrm{C}\right)$ and refluxing of the resulting liquor for 16 hours, the resulting liquor was processed as described above. The resulting solids, if any, washed several times with de-ionized water and vacuum dried for 72 hours before determination of weights of solids left on the filter membranes, if any. The reference test was also performed in duplicate with composite samples which did not contain any of the antiscalant polymers.

\section{RESULTS AND DISCUSSSION}

Fouling of the evaporator from sodium aluminosilicate scale has a significant impact. The mitigation or minimization of fouling has led to feed segregation and reduced waste processing flexibility. Additionally, cleaning costs in the nuclear environment have proven to be substantial. Application of a scale inhibitor, therefore, has obvious advantages. However, a successful deployment must meet the following attributes: 


\section{WM'08 CONFERENCE, FEBRUARY 24 - FEBRUARY 28, 2008, TUCSON, AZ WSRC-STI-2008-00097}

- Delays the formation of sodium aluminosilicate (NAS) in the evaporator

- Has a short life span under radiation fields to precipitate NAS in the drop tanks of the evaporator systems

- Does not generate flammable gases upon decomposition (radiolytic/chemical)

- Does not have any downstream impacts

In this study, the radiation stability of the proposed NAS inhibitors was examined. Two forms of testing were conducted. Firstly, tests were performed where the inhibitor agents were placed in a waste simulant that contained aluminate ion and irradiated to a specific radiation dose. In these tests, the inhibitor agents were added at the expected performance level (300 ppm). After irradiation, silicon in the form of metasilicate ion is added and the mixture is heated for 24 hours. In the second set of tests, the inhibitors were added at a higher concentration (1500 ppm), irradiate to a specific radiation dose and then analyzed by size exclusion chromatography.

Figure 1 shows the plot of normalized scale growth for each of the three scale inhibitors as a function of radiation dose from 0 to $10 \mathrm{Mrad}$. The measurement of scale growth relates the amount of NAS solids form in the inhibited test against that produced from a control test without inhibitor. Below 50 krad exposure level, these normalized scale growth plots show that both Epsilon and Tau inhibitors almost completely suppressed NAS formation. Below 50 krad exposure of the Omega-doped samples NAS suppression by Omega was limited to a range of about $60-82 \%$ effectiveness. The Omega inhibitor did not fare that well in the suppression of NAS formation, especially above the 50 kilo-rad exposure level for the reaction mixtures. On the other hand, both Epsilon and Tau inhibitors seemed to perform well in suppressing NAS formation past the 1 Mrad exposure level. The NAS suppression performance for both Epsilon and Tau antiscalants seems to start fading below 80\% after about 5 mega-rad exposure. By 10 Mrad the effectiveness of the Epsilon antiscalant is zero, while the Tau antiscalant still shows about 5\% effectiveness. However, from the potential application at SRS for this NAS inhibitor technology in a nuclear environment, these data show all three inhibitors would work well. The dose the inhibitor is expected to receive is less than 20 Mrad. Therefore, all of the inhibitors meet the expectation of preventing scale during the evaporation process.

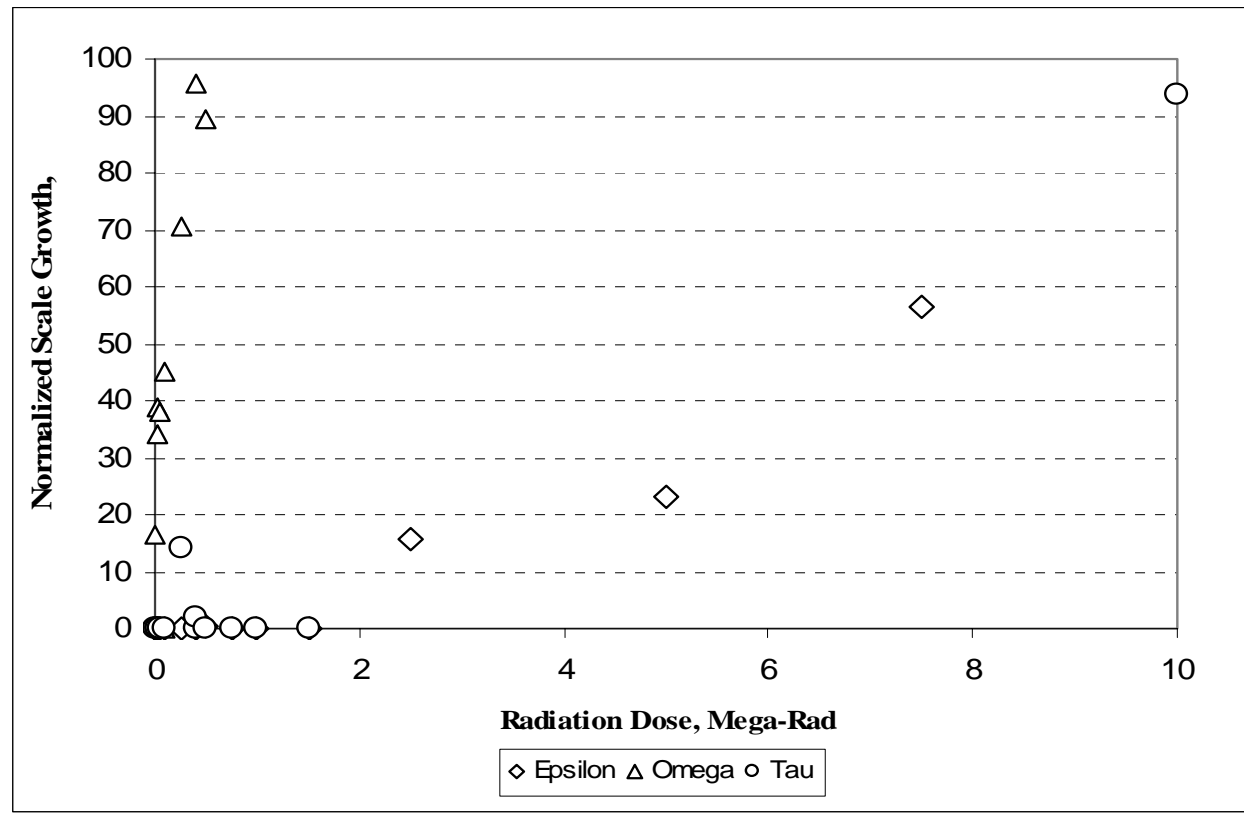

Fig.1. Plot of Scale Inhibitors Performance as a Function of Absorbed Radiation Dose 


\section{WM'08 CONFERENCE, FEBRUARY 24 - FEBRUARY 28, 2008, TUCSON, AZ WSRC-STI-2008-00097}

When examining the data from Figure 1 from the stand point of preventing downstream impact, it appears that the Omega inhibitor decomposes rapidly and the Epsilon and Tau materials survive the radiation. A rapid decomposition allows for the precipitation of aluminosilicate in the drop tank of the evaporator system. Depending on the actinide concentrations in the supernate liquor, precipitation is favored due to the presence of large amounts of sodium in the form of saltcake. Sodium can be credited as a neutron poison in the event that uranium is co-precipitated with the NAS solids as has been observed historically $[10,11]$. Therefore, from the data as a whole, the inhibitor that performs the best and meets the first two attributes is the inhibitor Omega since there is adequate performance during evaporation and rapidly stops preventing NAS precipitation.

However, preventing NAS precipitation is not the entire picture. The ideal inhibitor would perform during evaporation, allow NAS precipitation within the evaporator system, and not lead to downstream impacts. Testing was performed to examine the latter impacts via the second set of testing where the inhibitors were irradiated and subjected to analytical characterization with size exclusion chromatography. Shown in Figure 2 are the results of quantifying the inhibitor concentration as a function of dose for Omega and Epsilon respectively. The Epsilon inhibitor shows the most rapid decomposition. However, both inhibitors decompose rapidly enough to have completely decomposed prior to de-inventorying the waste out of the evaporator system.

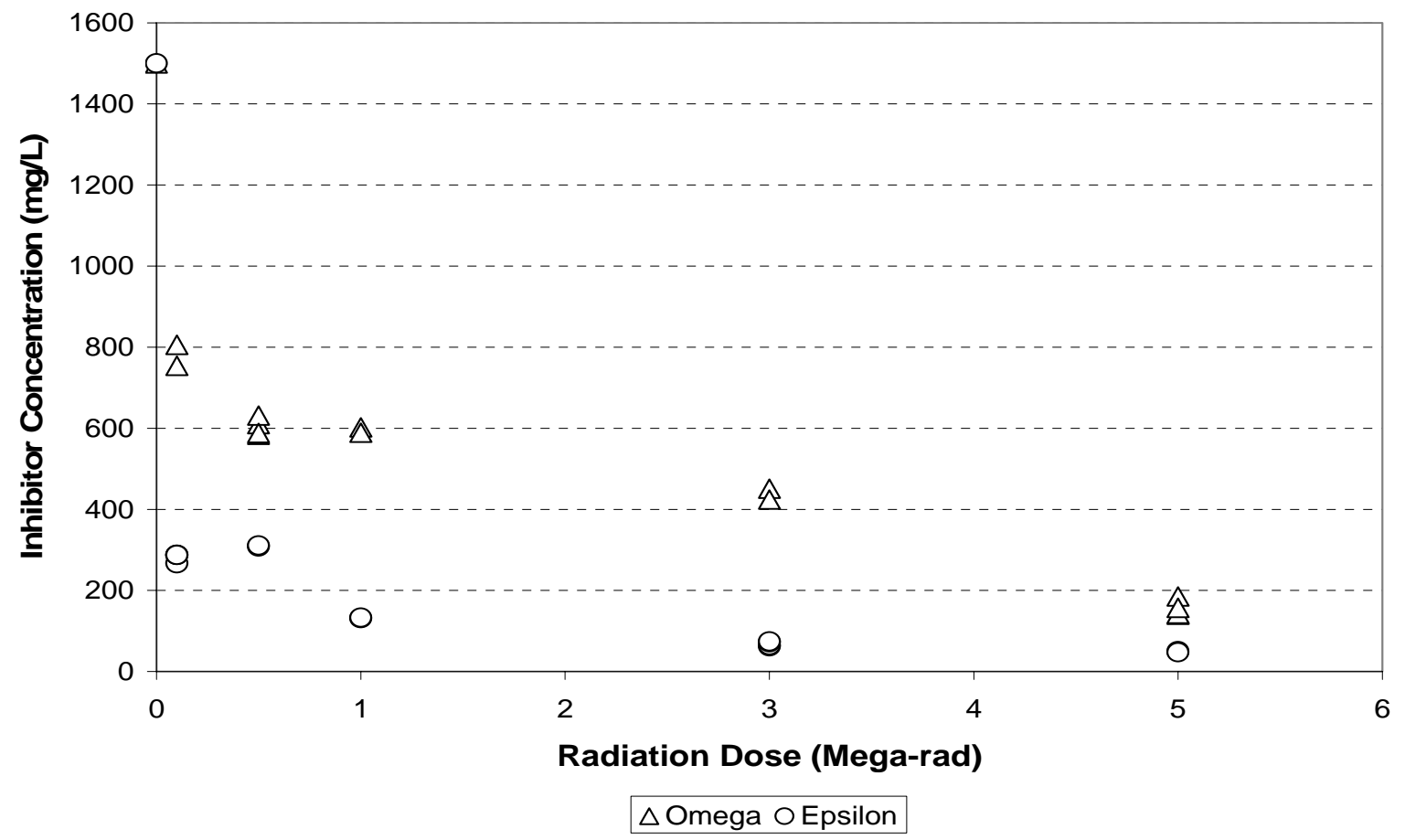

Fig.2. Plot of Inhibitor Concentration as a Function of Dose

In order to ensure that the potential application of the inhibitor technology will perform as expected in actual nuclear service, the inhibitors were tested in an actual waste sample that had previously had actinides, cesium and strontium removed. Table II contains the results of testing the three inhibitors for preventing NAS solids formation. The inhibitor dosage was $300 \mathrm{ppm}$ in these tests. Due to a limited quantity of actual waste these tests were single runs. Within the expected experimental uncertainty, each of the inhibitors prevented solids formation. 
WM'08 CONFERENCE, FEBRUARY 24 - FEBRUARY 28, 2008, TUCSON, AZ WSRC-STI-2008-00097

Table II. Percent Normalized NAS Scale Growth Results for Tests with Actual Waste

\begin{tabular}{|l|c|}
\hline Sample ID & Percent Normalized NAS Scale Growth \\
\hline Reference & 100 \\
\hline Epsilon & 0 \\
\hline Omega & 8 \\
\hline Tau & 8 \\
\hline
\end{tabular}

Figure 3 provides plots of the plutonium concentrations as a function of time for the tests with each of the three potential inhibitors and the test without an inhibitor. Additionally, data are shown for the actinide-containing waste simulant with and without inhibitor and no addition of MST. Inspection of Figure 3 reveals that the addition of $900 \mathrm{mg} / \mathrm{L}$ of each of the polymers did not adversely impact the removal of plutonium, neptunium or uranium from the simulated waste solution upon contact with MST. For plutonium, results, the average decontamination factors for MST and for MST plus the polymers are not statistically different at the two sigma interval. However, for plutonium and neptunium, the 168-h contact results indicate that the addition of two of the inhibitors polymers produced higher removal of plutonium and neptunium than the baseline MST. Given these results we conclude that the addition of $900 \mathrm{mg} / \mathrm{L}$ of each of the polymers does not adversely impact the removal plutonium, neptunium or uranium by MST.

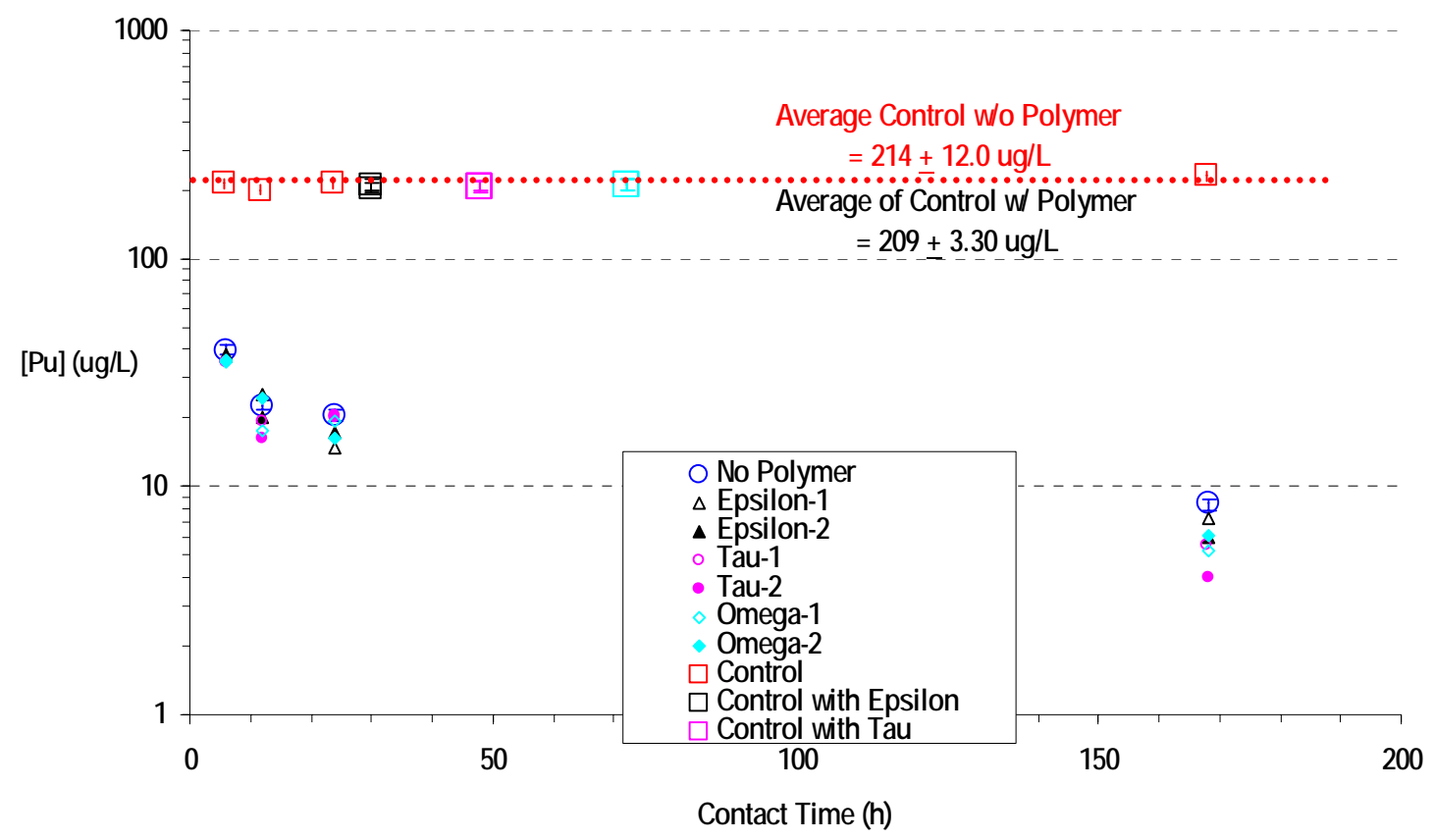

Fig.3. Plutonium Concentrations as a Function of Time

The first evaluation of the impact to the solvent extraction process used a conservative approach by adding fresh polymer solution to $90 \mathrm{~mL}$ of simulated HLW salt solution containing ${ }^{137} \mathrm{Cs}$. For extraction step of the process, the solvent was added to the separatory funnels containing the aqueous solutions. Five minutes after mixing, the samples that contained the polymers appeared to have milky white solvent layers. After a few hours of separation, the solvent layers for Tau and Omega samples are clear, and solvent layer for Epsilon sample still appears milky. The sample containing Epsilon 


\section{WM'08 CONFERENCE, FEBRUARY 24 - FEBRUARY 28, 2008, TUCSON, AZ WSRC-STI-2008-00097}

inhibitor was also much slower in separating into two layers when compared to the other samples. Figure 4 shows a picture of the samples after a few hours of separation. Examination of the Cs-137 counting data for the extraction, scrub and strip batch contacts show no impact of the inhibitor on the cesium behavior. The equilibrium batch distribution coefficients calculated from each of the tests with the inhibitor agreed within experimental error from the data from the control set of tests.

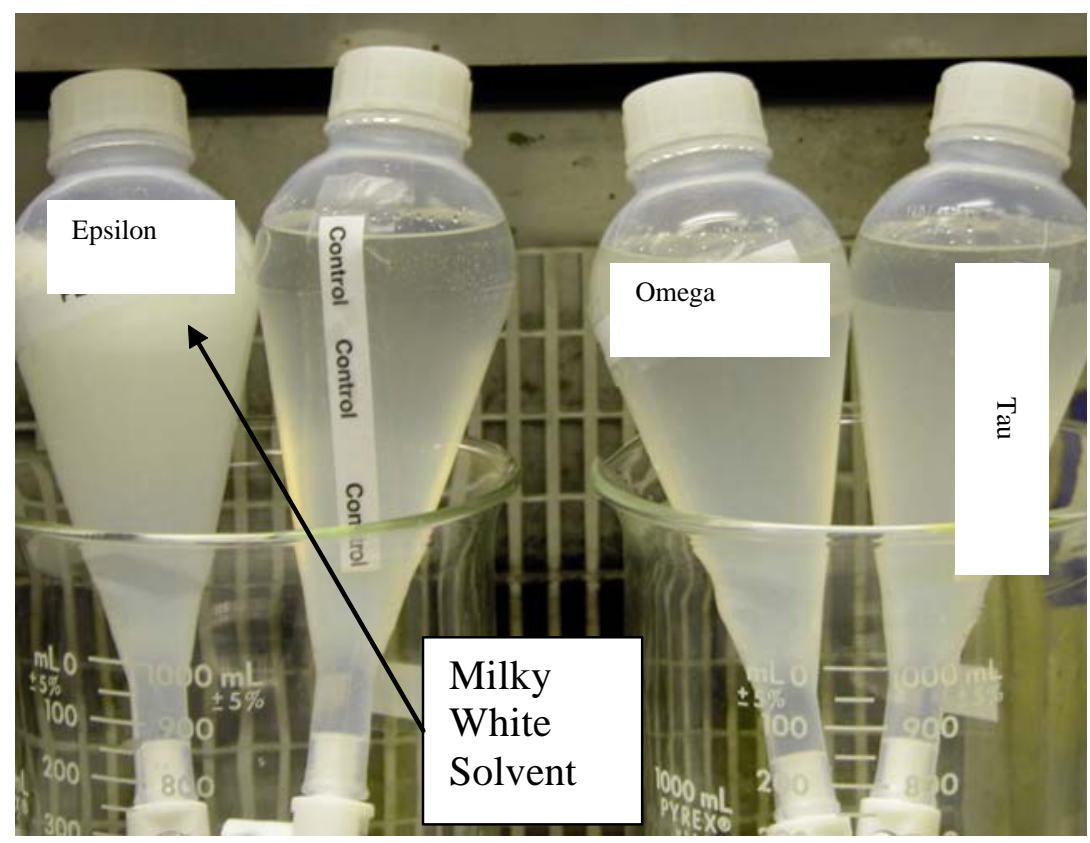

Fig. 4. Evaluation of ESS Process - Extraction Step After a Few Hours of Mixing

The last aspect of the screening tests was to examine the fate of polymers within the evaporator system. Testing involved containing the polymer-containing salt solution with sludge and salt cake and actually producing salt cake from a salt solution containing the polymers. It was noted that the samples that contained $300 \mathrm{ppm}$ and $1500 \mathrm{ppm}$ of the polymers tended to entrain air/foam upon shaking. The Epsilon polymer seemed to entrain air/foam the worst. However, the foam for the Omega and Tau samples dissipated in a few minutes while sustained foam was observed for the samples containing Omega that lasted the entire test period ( 168 hours). For the samples that contained $1500 \mathrm{ppm}$ of the polymers, it was noted that these samples tended to entrain more air/foam upon shaking then the 300 ppm samples.

Results of the sludge, salt and in-situ formed salt indicate that the sorption of the polymers onto the sludge solids is likely. It is not known whether or not there is a concentration limit for the sorption of the polymer to the sludge solids or if different solution chemistries impact the sorption ability of the polymer. Additionally, during the 168 hour test, the samples that contained the Epsilon polymer seemed to have a slower sludge settling rate than the other samples. Polymer was found in the condensates produced during the evaporation to produce salt cake. However, the polymer amounts in the condensates and the organic rings observed in the evaporator pots could be an artifact of the experimental setup, since limited volume separated the boiling solution from the condenser and no demister was in place to prevent liquid entrainment. Table III, Table IV, and Table V shows the relative amount of organic found adhered to either the salt of sludge from the above mentioned tests. 


\section{WM'08 CONFERENCE, FEBRUARY 24 - FEBRUARY 28, 2008, TUCSON, AZ WSRC-STI-2008-00097}

Table III. Results for the 1500 ppm Inhibitor Sludge Sorption Tests

\begin{tabular}{|c|c|c|c|c|c|}
\hline $\begin{array}{l}\text { Sample } \\
\text { Name }\end{array}$ & $\begin{array}{l}\text { Projected } \\
\text { Total } \\
\text { Organic } \\
\text { in } \\
\text { Samples } \\
\text { (g) }\end{array}$ & $\begin{array}{l}\text { Total } \\
\text { Organic } \\
\text { Carbon } \\
\text { from } \\
\text { Analysis } \\
\text { of } \\
\text { Superna } \\
\text { te (g) }\end{array}$ & $\begin{array}{l}\text { Total } \\
\text { Organ } \\
\text { ic } \\
\text { Carbo } \\
\mathbf{n} \text { from } \\
\text { Analys } \\
\text { is of } \\
\text { Sludge } \\
\text { (g) }\end{array}$ & $\begin{array}{l}\text { Total } \\
\text { Organ } \\
\text { ic } \\
\text { Carbo } \\
\text { n } \\
\text { Presen } \\
\text { t in } \\
\text { Sampl } \\
\text { e } \\
(g)^{a}\end{array}$ & $\begin{array}{l}\text { Weight } \\
\text { Percent } \\
\text { of } \\
\text { Organic } \\
\text { Carbon } \\
\text { in } \\
\text { Sludge } \\
\text { Solids } \\
(W t . \%)^{b}\end{array}$ \\
\hline $\begin{array}{l}\text { Epsilon- } \\
1\end{array}$ & 2.05E-01 & $\begin{array}{l}3.32 \mathrm{E}- \\
02\end{array}$ & $\begin{array}{l}1.36 \mathrm{E}- \\
01\end{array}$ & $\begin{array}{l}1.69 \mathrm{E}- \\
01\end{array}$ & $8.04 \mathrm{E}+01$ \\
\hline $\begin{array}{l}\text { Epsilon- } \\
2\end{array}$ & 2.05E-01 & $\begin{array}{l}5.10 \mathrm{E}- \\
02\end{array}$ & $\begin{array}{l}1.54 \mathrm{E}- \\
01\end{array}$ & $\begin{array}{l}2.05 \mathrm{E}- \\
01\end{array}$ & $7.51 \mathrm{E}+01$ \\
\hline Omega-1 & $1.91 \mathrm{E}-01$ & $\begin{array}{l}8.18 \mathrm{E}- \\
02\end{array}$ & $\begin{array}{l}1.20 \mathrm{E}- \\
01\end{array}$ & $\begin{array}{l}2.02 \mathrm{E}- \\
01\end{array}$ & $5.94 \mathrm{E}+01$ \\
\hline Omega-2 & 1.91E-01 & $\begin{array}{l}4.36 \mathrm{E}- \\
02\end{array}$ & $\begin{array}{l}1.20 \mathrm{E}- \\
01\end{array}$ & $\begin{array}{l}1.63 \mathrm{E}- \\
01\end{array}$ & 7.33E +01 \\
\hline Tau-1 & 2.27E-01 & $\begin{array}{l}5.47 \mathrm{E}- \\
02\end{array}$ & $\begin{array}{l}\text { 1.57E- } \\
01\end{array}$ & $\begin{array}{l}2.12 \mathrm{E}- \\
01\end{array}$ & $7.42 \mathrm{E}+01$ \\
\hline Tau-2 & 2.26E-01 & $\begin{array}{l}1.07 \mathrm{E}- \\
01\end{array}$ & $\begin{array}{l}\text { 1.83E- } \\
01\end{array}$ & $\begin{array}{l}2.90 \mathrm{E}- \\
01\end{array}$ & $6.31 \mathrm{E}+01$ \\
\hline
\end{tabular}

${ }^{\mathrm{a}}$ Results reported are the addition of columns 3 and 4.

${ }^{\mathrm{b}}$ Weight percent calculated by dividing Column 4 by column 5 and multiplying by 100 .

Table IV. Results for the 300 ppm and 1500 ppm Inhibitor Salt Sorption Tests

\begin{tabular}{|c|c|c|c|c|}
\hline $\begin{array}{l}\text { Sample } \\
\underline{\text { Name }}\end{array}$ & $\begin{array}{c}\frac{\underline{\text { Total }}}{\text { Grams }} \\
\text { of Organic } \\
\frac{\text { Carbon in }}{\text { Liquor }^{\mathrm{a}}}\end{array}$ & $\frac{\frac{\text { Grams of }}{\text { Polymer }}}{\underline{\text { Added }}}$ & $\frac{\frac{\text { Grams of }}{\text { Organic }}}{\frac{\text { Carbon }}{\text { From }}}$ & $\frac{\frac{\text { Wt.\% of }}{\text { Polymer in }}}{\underline{\text { Liquor }}^{\mathrm{C}}}$ \\
\hline Epsilon 300ppm\#1 & 2.39E-03 & $1.02 \mathrm{E}-02$ & 5.42E-03 & $4.42 \mathrm{E}+01$ \\
\hline Omega 300ppm\#1 & $1.56 \mathrm{E}-03$ & $1.11 \mathrm{E}-02$ & 5.40E-03 & $2.89 \mathrm{E}+01$ \\
\hline Tau 300ppm\#1 & $2.01 \mathrm{E}-03$ & $1.05 \mathrm{E}-02$ & 6.19E-03 & $3.25 \mathrm{E}+01$ \\
\hline Epsilon 1500ppm\#1 & $2.09 \mathrm{E}-03$ & $5.24 \mathrm{E}-02$ & $2.80 \mathrm{E}-02$ & $7.48 \mathrm{E}+00$ \\
\hline Omega 1500ppm\#1 & $1.66 \mathrm{E}-03$ & $5.22 \mathrm{E}-02$ & $2.55 \mathrm{E}-02$ & $6.51 \mathrm{E}+00$ \\
\hline
\end{tabular}


WM'08 CONFERENCE, FEBRUARY 24 - FEBRUARY 28, 2008, TUCSON, AZ

WSRC-STI-2008-00097

\begin{tabular}{|c|c|c|c|c|}
\hline Tau 1500ppm\#1 & $2.32 \mathrm{E}-03$ & $5.15 \mathrm{E}-02$ & $3.05 \mathrm{E}-02$ & $7.61 \mathrm{E}+00$ \\
\hline
\end{tabular}

${ }^{\mathrm{a}}$ Only one sample analyzed

${ }^{\mathrm{b}}$ Multiplied Column 4 by carbon fractions (Epsilon $=0.534$, Omega $=0.489$, and Tau $=0.592$ ) reported by Cytec for the polymers to obtain total organic carbon values.

${ }^{\mathrm{c}}$ Weight percent calculated by dividing column 3 by column 5 and multiplying by 100 . 
Table V. Results for the 1500 ppm Inhibitor Evaporator Tests

\begin{tabular}{|c|c|c|c|c|}
\hline Sample Name & $\underline{\text { TOC }} \underline{\underline{a}}$ & 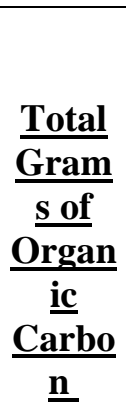 & $\begin{array}{l}\frac{\text { Grams }}{\underline{\text { of }}} \\
\frac{\text { Organ }}{\underline{\text { ic }}} \\
\frac{\text { Carbo }}{\underline{n}} \\
\frac{\text { From }}{\text { Polym }} \\
\underline{\text { er }}^{\mathbf{b}}\end{array}$ & $\frac{\text { Wt. \% of }}{\text { Polymer }^{\underline{c}}}$ \\
\hline Epsilon Liquor & $\begin{array}{c}3.99 \mathrm{E}+02 \\
\mathrm{mg} / \mathrm{L}\end{array}$ & $\begin{array}{l}5.0 \mathrm{E}- \\
02\end{array}$ & $\begin{array}{c}4.01 \mathrm{E}- \\
01\end{array}$ & $1.25 \mathrm{E}+01$ \\
\hline Omega Liquor & $\begin{array}{c}4.82 \mathrm{E}+02 \\
\mathrm{mg} / \mathrm{L}\end{array}$ & $\begin{array}{c}6.3 \mathrm{E}- \\
02\end{array}$ & $\begin{array}{c}3.67 \mathrm{E}- \\
01\end{array}$ & $1.72 \mathrm{E}+01$ \\
\hline Tau Liquor & $\begin{array}{c}5.81 \mathrm{E}+02 \\
\mathrm{mg} / \mathrm{L}\end{array}$ & $\begin{array}{c}7.2 \mathrm{E}- \\
02\end{array}$ & $\begin{array}{c}4.44 \mathrm{E}- \\
01\end{array}$ & 1.63E+01 \\
\hline $\begin{array}{l}\text { Epsilon } \\
\text { Condensate }\end{array}$ & $\begin{array}{c}4.47 \mathrm{E}+02 \\
\mathrm{mg} / \mathrm{L}\end{array}$ & $\begin{array}{c}1.55 \mathrm{E}- \\
01\end{array}$ & $\begin{array}{c}4.01 \mathrm{E}- \\
01\end{array}$ & $3.87 \mathrm{E}+01$ \\
\hline $\begin{array}{l}\text { Omega } \\
\text { Condensate }\end{array}$ & $\begin{array}{c}5.12 \mathrm{E}+02 \\
\mathrm{mg} / \mathrm{L}\end{array}$ & $\begin{array}{c}1.90 \mathrm{E}- \\
01\end{array}$ & $\begin{array}{c}3.67 \mathrm{E}- \\
01\end{array}$ & $5.19 \mathrm{E}+01$ \\
\hline Tau Condensate & $\begin{array}{c}7.95 \mathrm{E}+02 \\
\mathrm{mg} / \mathrm{L}\end{array}$ & $\begin{array}{c}2.61 \mathrm{E}- \\
01\end{array}$ & $\begin{array}{c}4.44 \mathrm{E}- \\
01\end{array}$ & $5.87 \mathrm{E}+01$ \\
\hline $\begin{array}{l}\text { Epsilon Dissolved } \\
\text { Salt }\end{array}$ & $\begin{array}{c}5.84 \mathrm{E}+02 \\
\mathrm{mg} / \mathrm{kg}\end{array}$ & $\begin{array}{l}2.3 \mathrm{E}- \\
02\end{array}$ & $\begin{array}{c}4.01 \mathrm{E}- \\
01\end{array}$ & $5.74 \mathrm{E}+00$ \\
\hline Omega Salt & $\begin{array}{c}5.89 \mathrm{E}+02 \\
\mathrm{mg} / \mathrm{kg}\end{array}$ & $\begin{array}{c}2.8 \mathrm{E}- \\
02\end{array}$ & $\begin{array}{c}3.67 \mathrm{E}- \\
01\end{array}$ & $7.69 \mathrm{E}+00$ \\
\hline Tau Salt & $\begin{array}{c}9.16 \mathrm{E}+02 \\
\mathrm{mg} / \mathrm{kg}\end{array}$ & $\begin{array}{c}4.9 \mathrm{E}- \\
02\end{array}$ & $\begin{array}{c}4.44 \mathrm{E}- \\
01\end{array}$ & $1.10 \mathrm{E}+01$ \\
\hline
\end{tabular}

${ }^{\mathrm{a}}$ Only one sample analyzed

${ }^{\mathrm{b}}$ Mass of polymer added $(0.75 \mathrm{~g})$ was multiplied by carbon fractions (Epsilon $=0.534$, Omega $=0.489$, and Tau $=0.592$ ) reported by Cytec for the polymers to obtain total organic carbon values.

${ }^{\mathrm{c}}$ Weight percent calculated by dividing column 3 by column 5 and multiplying by 100 . Carbon amounts summed for the liquor, condensate, and salt do not equal 100, due to organic ring formation in evaporator pot.

\section{CONCLUSIONS}

A successful application of the NAS scale inhibitor technology for nuclear plant operations bring a plethora of constraints that typically would not exist in an industrial setting. In this work, three potential scale inhibitors have been examined as to the radiation stability or perhaps better stated limited radiation stability with regards to preventing aluminosilicate scales in the waste evaporators. 


\section{WM'08 CONFERENCE, FEBRUARY 24 - FEBRUARY 28, 2008, TUCSON, AZ WSRC-STI-2008-00097}

The program at its onset examined possible negative impacts that the inhibitor technology could have in the various processing and storage facilities in the HLW system at SRS. A large number of potential impacts were then weighed against criteria associated with cost, schedule and safety. Table I summarized the severity and number of each risk. Testing protocols were developed to address a number of the high and medium risks based on information exchanges with Cytec industries concerning the chemistry of the potential inhibitors.

The desired outcome of an inhibitor application would be for the inhibitor to survive radiolytic and chemical degradation long enough for the waste to be evaporated and then decompose rapidly. Of the three potential inhibitors tested, all three show acceptable performance for preventing NAS solids formation without radiation in simulated wastes and in an actual waste matrix. One inhibitor, Omega, appears to survive the harsh conditions within the evaporator (chemical, radiolytic and thermal) but decomposes rapidly as a function of absorbed dose.

One of the potential inhibitors, Tau, was excluded during the screening tests based on discussions with Cytec concerning the probability of scaling the production to the commercial stage and the time to market based on their experience. Therefore, the tested risks, omega had one high residual risk and nine medium risks. Epsilon, on the other hand, and 6 residual high risks and 12 medium risks. Therefore, based on the residual risk profile and the unique radiolytic stability of the Omega inhibitor, the Omega inhibitor was selected for further development. Efforts are currently underway to synthesize industrial scale quantities of the NAS inhibitor for final testing prior to deployment in an SRS highlevel waste evaporator.

\section{REFERENCES}

1. J. Addai-Mensah A. R. Gerson, K. Zheng, A. O'Dea, and R. St.C. Smart, Light Metals (1997) 23-28.

2. A. R. Gerson and K. Zheng, J. Crystal Growth 171 (1997) 209-218.

3. G. I. D. Roach and J. B. Cornell, Chemeca 85: Innovation Process Resour. Ind., Aust. Chem. Eng. Conf., $13^{\text {th }}$ (1985) 217-222.

4. K. Yamada, M. Yoshihara, and S. Tasaka, Light Metals (1985) 223-235.

5. B.R. Bickmore, K.L. Nagy, J.S. Young and J.W. Drexler. Environ. Sci. Technol., 35 4481-4486 (2001).

6. P. Ulmgren, Nordic Pulp and Paper Res. J. 2(1) 4-9 (1987).

7. H. Park, and Englezos, Ind. Eng. Chem Res. Vol. 38 4959-4965(1999).

8. J. Addai-Mensah, J. Li, M. Zbik, and W. Wilmarth, Chemeca 2005, Conference Proceedings, 1 - 7, Brisbane Queensland, Australia, Smart Soutions Doing More with less, Chemeca, 2005.

9. W. R. Wilmarth, S. W. Rosencrance, D. T. Hobbs, C. M. Jantzen, J. E. Laurinat, W. B. Van Pelt, W. L. Tamosaitis, A. J. Mattus, M. Z. Hu, D. W. DePaoli, C. F. Weber, C. P. McGinnis, S. Mattigod, "Aluminosilicate Formation in High Level Waste Evaporators: A Mechanism for Uranium Accumulation” Proceedings of Waste Management ’02.

10. W. R. Wilmarth, M. C. Thompson, C. J. Martino, V. H. Dukes, J. T. Mills, C. Boley, and B. L. 


\section{WM'08 CONFERENCE, FEBRUARY 24 - FEBRUARY 28, 2008, TUCSON, AZ WSRC-STI-2008-00097}

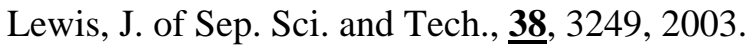

11. J. Addai-Mensah, J. Li, M. Zbik and W. Wilmarth, Light Metals, 2005, Minerals, Metals, and Materials Society, p. 171.

12. J. Addai-Mensah, J. Li, M. Zbik, and W. R. Wilmarth, J. of Sep. Sci. and Tech., 40, 267, 2005.

13. Addai-Mensah, J., Gerson, A.R., Jones, R. and Zbik, M., Light Metals (2001) 13-18.

14. D.P. Spitzer, A.S. Rothenberg, H.I. Heitner, F. Kula, US Patent No 20040011744 (2004), D. Spitzer, A. Rothenberg, H.I. Heitner, F. Kula, M.Lewellyn, Light Metals, 183-188 (2005).

15. D. D. Walker, M. A. Norato, S. G. Campbell, M. J. Crowder, S. D. Fink, F. F. Fondeur, M. W. Geeting, G. F. Kessinger, and R. A. Pierce, J. Sep. Sci. and Tech., 40, p. 297, 2005. 